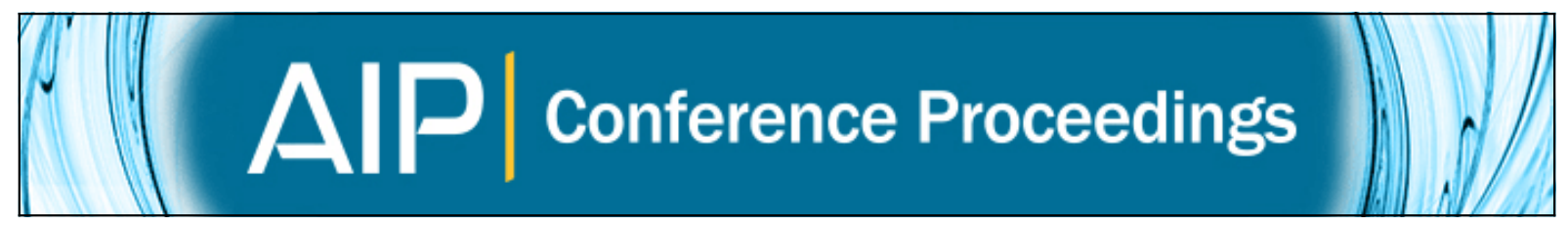

\title{
Role of organics in particle nucleation: From the lab to global model
}

Josef Dommen, Francesco Riccobono, Siegfried Schobesberger, Federico Bianchi, Catherine Scott, Ismael K. Ortega, Linda Rondo, Martin Breitenlechner, Heikki Junninen, Neil M. Donahue, Andreas Kürten, Arnaud Praplan , Ernest Weingartner, Armin Hansel, Joachim Curtius, Jasper Kirkby, Markku Kulmala, Kenneth S. Carslaw, Douglas R. Worsnop, Urs Baltensperger, and CLOUD Collaboration

Citation: AIP Conference Proceedings 1527, 330 (2013); doi: 10.1063/1.4803270

View online: http://dx.doi.org/10.1063/1.4803270

View Table of Contents: http://scitation.aip.org/content/aip/proceeding/aipcp/1527?ver=pdfcov

Published by the AIP Publishing

\section{Articles you may be interested in}

The role of highly oxidized organics in new particle formation

AIP Conf. Proc. 1527, 359 (2013); 10.1063/1.4803277

From global and semantic evaluations to physical measurements and modeling

J. Acoust. Soc. Am. 122, 3011 (2007); 10.1121/1.2942758

Nucleating cavitation from laser-illuminated nano-particles

ARLO 6, 138 (2005); 10.1121/1.1897823

Observations and models of particle nucleation near cloud outflows

AIP Conf. Proc. 534, 831 (2000); 10.1063/1.1361988

The role of chain folding in the crystallization kinetics of nucleated polypropylene: An elementary model J. Appl. Phys. 81, 2995 (1997); 10.1063/1.364332 


\title{
Role of Organics in Particle Nucleation: From the Lab to Global Model
}

\author{
Josef Dommen $^{\mathrm{a}}$, Francesco Riccobono ${ }^{\mathrm{a}}$, Siegfried Schobesberger ${ }^{\mathrm{b}}$, \\ Federico Bianchi ${ }^{a}$, Catherine Scott ${ }^{\mathrm{c}}$, Ismael K. Ortega ${ }^{\mathrm{b}}$, Linda Rondo ${ }^{\mathrm{d}}$, \\ Martin Breitenlechner ${ }^{\mathrm{e}}$, Heikki Junninen ${ }^{\mathrm{b}}$, Neil M. Donahue ${ }^{\mathrm{f}}$, Andreas \\ Kürten ${ }^{\mathrm{d}}$, Arnaud Praplan ${ }^{\mathrm{a}}$, Ernest Weingartner ${ }^{\mathrm{a}}$, Armin Hansel ${ }^{\mathrm{e}}$, Joachim \\ Curtius ${ }^{\mathrm{d}}$, Jasper Kirkby ${ }^{\mathrm{g}}$, Markku Kulmala ${ }^{\mathrm{b}}$, Kenneth S. Carslaw ${ }^{\mathrm{c}}$, \\ Douglas R. Worsnop ${ }^{\mathrm{b}, \mathrm{h}}$, Urs Baltensperger ${ }^{\mathrm{a}}$ and the CLOUD collaboration \\ ${ }^{a}$ Laboratory of Atmospheric Chemistry, Paul Scherrer Institute, 5232 Villigen, Switzerland \\ ${ }^{b}$ University of Helsinki, Department of Physics, FI-00014 Helsinki, Finland \\ ${ }^{c}$ University of Leeds, School of Earth and Environment, LS2-9JT Leeds, United Kingdom \\ ${ }^{d}$ Goethe-University of Frankfurt, Institute for Atmospheric and Environmental Sciences, 60438 \\ Frankfurt am Main, Germany \\ ${ }^{e}$ University of Innsbruck, Institute for Ion and Applied Physics, 6020 Innsbruck, Austria \\ ${ }^{f}$ Center for Atmospheric Particle Studies, Carnegie Mellon University, Pittsburgh, PA 15217, USA \\ ${ }^{g}$ CERN, 1211 Geneva, Switzerland \\ ${ }^{h}$ Aerodyne Research Inc., Billerica, Massachusetts 01821, USA
}

\begin{abstract}
The role of oxidized organic compounds in the process of new particle formation in the atmosphere is poorly known. Here we used the ultraclean and most sophisticated CLOUD chamber to investigate systematically particle formation in the presence of sulfuric acid and oxidized organics. We varied independently the concentrations of both of these components. In addition, nucleation was observed without and in the presence of ionic compounds. From the results a new parameterized description of nucleation was derived for global climate model simulations.
\end{abstract}

Keywords: Nucleation, sulfuric acid, oxidized organics, cluster, atmosphere, climate change.

PACS: 92.60.Mt, 64.60.Q, 92.60.hf

\section{INTRODUCTION}

Atmospheric particles are produced either by direct emissions or are formed by gasto-particle processes, called nucleation. Global models predict that $45 \%$ of cloud condensation nuclei (CCN) are secondary aerosols [1]. Besides their direct effect on radiation by scattering and absorbing light these aerosols also influence cloud formation and properties. This indirect effect on climate may be large but hitherto it is only poorly quantified [2]. First of all, the formation of new particles in the atmosphere is a poorly understood process and secondly the aerosol-cloud interaction needs to be represented in a highly parameterized form in global models. In recent years sulfuric acid $\left(\mathrm{H}_{2} \mathrm{SO}_{4}\right)$ has emerged as the key player in atmospheric nucleation. It is formed by photo-oxidation of sulfur dioxide in one step and has an extremely low 
vapor pressure. In many field campaigns a good correlation between the concentration of $\mathrm{H}_{2} \mathrm{SO}_{4}$ and the rate of particle nucleation has been established. However, in many regions of the world the sulfuric acid concentrations are way too low to explain the observed nucleation by binary $\mathrm{H}_{2} \mathrm{SO}_{4}-\mathrm{H}_{2} \mathrm{O}$ homogeneous nucleation. A third vapor component is required to stabilize the smallest clusters which are then able to grow to nanometer sized particles. Recent laboratory experiments have shown that ammonia can stabilize $\mathrm{NH}_{3}-\mathrm{H}_{2} \mathrm{SO}_{4}-\mathrm{H}_{2} \mathrm{O}$ clusters but this ternary nucleation is only able to account for the rates observed in the atmosphere at lower temperatures [3]. This stabilization of a cluster by an acid-base pair could be a viable mechanism and other base molecules have been suggested to foster nucleation. A well-known class of such molecules present in the atmosphere are amines. Quantum chemical calculations have shown that amines form even stronger bonds with $\mathrm{H}_{2} \mathrm{SO}_{4}$ than $\mathrm{NH}_{3}$ and may thus further stabilize small clusters [4]. There are also several studies providing experimental evidence that amines support ambient nucleation [5, 6]. Oxidized organic vapors, another class of compounds that are ubiquitously present in the atmosphere, have also been suggested to be involved in nucleation. Experimental evidence from ambient measurements is not well established and hampered by the lack of appropriate instrumentation and the fact that the formation of oxidized organic species and sulfuric acid are strongly coupled in the ambient atmosphere. Laboratory studies could show a dependence of new particle formation on oxidized organics $[7,8]$ but there is no direct observation available with respect to the underlying mechanism. What is necessary are very well controlled experiments and the most advanced instrumentation able to detect and resolve the key species of nucleation at the molecular and cluster level.

The CLOUD project provides a unique platform to perform such demanding experiments. The CLOUD chamber has been established as the technologically most advanced and cleanest chamber worldwide. The latter property is a fundamental prerequisite to disentangle different processes which may be triggered at trace level concentrations of pollutants. Here we present experiments at the CLOUD chamber where $\mathrm{SO}_{2}$ and an organic molecule have been added to study nucleation under controlled photo-oxidation conditions. A parameterized scheme derived from the results was included into a global climate model to evaluate the potential influence on cloud condensation nuclei formation.

\section{CLOUD Chamber and Instrumentation}

The CLOUD chamber is a $26 \mathrm{~m}^{3}$ stainless steel chamber. It has a very precise temperature and humidity control. It is flushed with ultraclean air from liquid nitrogen and oxygen tanks and selected trace gases can be delivered in a controlled manner to keep stable conditions over hours. UV illumination from a fiber-optic system is used to produce $\mathrm{OH}$ radicals from the photolysis of ozone. A special feature is the adjustable pion beam provided by the CERN Proton Synchrotron allowing for the simulation of ionizing cosmic rays. On the other hand a $20 \mathrm{kV} / \mathrm{m}$ electric clearing field can be added to enforce an ion-free environment. A comprehensive suite of state-of-

the-art instruments was operated during these experiments. The gas measurements 
included: $\mathrm{SO}_{2}, \mathrm{O}_{3}$, dew point, $\mathrm{H}_{2} \mathrm{SO}_{4}$ with a chemical ionization mass spectrometer (CIMS), organic vapor concentrations with a proton transfer reaction time of flight (PTR-TOF) mass spectrometer, an ion chromatograph (IC) to measure ammonia $\left(\mathrm{NH}_{3}\right)$ and dimethylamine $\left(\mathrm{DMA}, \mathrm{C}_{2} \mathrm{H}_{7} \mathrm{~N}\right)$, and two atmospheric pressure interface time of flight (API-TOF) mass spectrometers for the composition of positively and negatively charged clusters. The particle measurements included a wide array of condensation particle counters (CPC) including particle size magnifiers (PSM; Airmodus 09), diethylene glycol CPCs and a TSI 3776.

\section{CLOUD Chamber Experiment}

Pinanediol ( $\mathrm{PD}, \mathrm{C}_{10} \mathrm{H}_{18} \mathrm{O}_{2}$ ) was used as a precursor to study the influence of organic species on nucleation. This compound was chosen as it does not have carboncarbon double bonds and does therefore not react with ozone. Ozone is always present in the CLOUD chamber to produce $\mathrm{OH}$ radicals by UV-photolysis. In addition, pinanediol is an oxidation product of $\alpha$-pinene photooxidation and can thus be considered a first generation oxidation product of a biogenic monoterpene compound (Fig. 1).

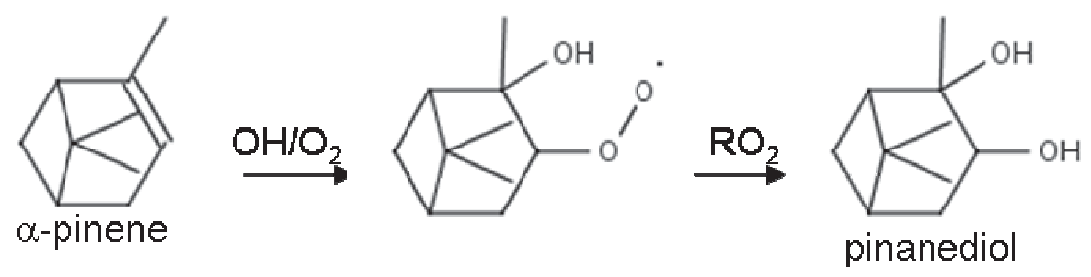

FIGURE 1. Pinanediol is a first generation product of the $\alpha$-pinene reaction with $\mathrm{OH}$ radicals. This molecule was used in the CLOUD chamber as a precursor for the nucleation study.

Pinanediol was evaporated in a temperature-controlled vessel and delivered to the chamber in a dilution flow. Additionally, $\mathrm{SO}_{2}$ and ozone were introduced to establish defined levels. After turning on the UV-lights ozone was photolyzed and $\mathrm{OH}$ radicals were formed which reacted with $\mathrm{SO}_{2}$ and pinanediol. Depending on the light level as well as the $\mathrm{SO}_{2}$ and pinanediol concentrations, various levels of sulfuric acid could be established and the rate of formation of pinanediol oxidation products (PDox) could be varied. Two regimes of conditions were produced. In one set of experiment sulfuric acid concentrations were kept more or less constant and PDox was varied, while in the second set of experiment PDox concentrations were kept constant and sulfuric acid was varied. By this approach the combined effect of varying $\mathrm{H}_{2} \mathrm{SO}_{4}$ and oxidized organics compounds could be disentangled. These experiments were performed under three conditions. First, the clearing field was on, sweeping away all ions in the chamber within a second such that nucleation happened without the influence of ions. Second, the naturally occurring galactic cosmic rays produced a level of ion pairs in the chamber typical of the atmospheric boundary layer and nucleation represented the sum of ion-induced and neutral processes. Third, with the charged ion beam the nucleation of the upper troposphere was simulated. 
The nucleation rates for all these conditions were measured and the formation of embryonic clusters was observed. Quantum chemical calculations have been performed to gain insight into the stability of sulfuric acid-oxidized organics clusters. An empirical dependence between the nucleation rate and sulfuric acid and oxidized organics was established. From this a parameterization was derived which was used for global climate model simulations.

\section{ACKNOWLEDGMENTS}

We would like to thank CERN for supporting CLOUD with important technical and financial resources, and for providing a particle beam from the CERN Proton Synchrotron. This research has received funding from the EC Seventh Framework Programme (Marie Curie Initial Training Network "CLOUD-ITN" no. 215072, MCITN "CLOUD-TRAIN" no. 316662, and ERC-Advanced "ATMNUCLE" grant no. 227463), the German Federal Ministry of Education and Research (project nos. 01LK0902A and 01LK1222A), the Swiss National Science Foundation (project nos. 200020_135307 and 206620_130527), the Academy of Finland (Center of Excellence project no. 1118615), the Academy of Finland (135054, 133872, 251427, 139656, 139995, 137749, 141217, 141451), the Finnish Funding Agency for Technology and Innovation, the Nessling Foundation, the Austrian Science Fund (FWF; project no. P19546 and L593), the Portuguese Foundation for Science and Technology (project no. CERN/FP/116387/2010), the Swedish Research Council, Vetenskapsrådet (grant 2011-5120), the Presidium of the Russian Academy of Sciences and Russian Foundation for Basic Research (grants 08-02-91006-CERN and 12-02-91522-CERN), and the U.S. National Science Foundation (grants AGS1136479 and CHE1012293).

\section{REFERENCES}

1. J. Merikanto, D.V. Spracklen, G.W. Mann, S.J. Pickering and K.S. Carslaw, Atmos.Chem.Phys.9, 8601-8616 (2009).

2. IPCC, Climate Change 2007: the Physical Science Basis. Contribution of Working Group I to the Fourth Assessment Report of the Intergovernmental Panel on Climate Change. Cambridge Univ. Press, (2007).

3. J. Kirkby et al., Nature 476, 429-433 (2011).

4. T. Kurtén, V. Loukonen, H. Vehkamäki and M. Kulmala, Atmos. Chem. Phys. 8, 4095-4103 (2008).

5. S.M. Murphy et al., Atmos.Chem. Phys. 7, 2313-1337 (2007).

6. J.N. Smith et al., Proc. Natl. Acad. Sci. USA 107, 6634-6639 (2010).

7. A. Metzger et al., Proc. Natl. Acad. Sci. USA 107, 6646-6651 (2010).

8. F. Riccobono et al., Atmos. Chem. Phys. 12, $9427-9439$ (2012). 